\title{
ELECTROCHEMICAL FUNCTIONALIZATION OF SINGLE WALL CARBON NANOTUBES WITH PHOSPHORUS AND NITROGEN SPECIES
}

\author{
Andrés Felipe Quintero-Jaime ${ }^{\mathrm{a}}$, Diego Cazorla-Amorós ${ }^{\mathrm{b}}$, Emilia Morallón $^{\mathrm{a}}$. \\ ${ }^{\text {a }}$ Departamento de Química Física and Instituto Universitario de Materiales de Alicante \\ (IUMA), University of Alicante, Ap. 99, 03080, Alicante, Spain \\ ${ }^{\mathrm{b}}$ Departamento de Química inorgánica and Instituto Universitario de Materiales de \\ Alicante (IUMA), University of Alicante, Ap. 99, 03080, Alicante, Spain
}

\begin{abstract}
Single Wall Carbon Nanotubes (SWCNTs) have been successfully functionalized by electrochemical oxidation in presence of 4-aminophenyl phosphonic acid (4-APPA). Electrochemical modification has been performed by cyclic voltammetry using different upper potential limits, producing the incorporation of $\mathrm{N}$ and $\mathrm{P}$ functionalities on $\mathrm{SWCNT}$ through polymerization reactions, although some covalent attachment cannot be discarded. Electrochemical oxidation in presence of CNT produces polymerization of 4APPA, what has been related to the interaction between monomer and the CNT surface. The voltammograms of the functionalized SWCNT show different well-defined redox processes that are maintained at high $\mathrm{pH}$. Raman spectroscopy shows that the structure of the SWCNT is maintained even at high potentials suggesting that oxidation selectively occurs in the 4-APPA monomer favoring polymer chain growth. The degree of modification of SWCNT can be easily controlled by selecting the electrochemical conditions.
\end{abstract}

*Corresponding author. e-mail: morallon@ua.es (Emilia Morallón); telf.: +34 965909590 


\section{Introduction}

Since their discovery, nanocarbon materials, such as carbon nanotubes (CNTs), have attracted the attention of researchers due to their outstanding mechanical, optical, chemical and electronic properties. However, these intrinsic properties are not usually obtained due to the difficulty in preparing high purity CNT with the desired structure, and their tendency to bundling [1]. This last aspect results in an important limitation from an application point of view since it impedes their effective dispersion in a solvent and their processability. Thus, one important aspect to facilitate further potential applications of CNTs lies in the proper surface modification to overcome the high van der Waals interactions between tubes, allowing their effective dispersion and proper processability [2,3]. There are different methodologies for CNT functionalization, which can be classified as covalent and non-covalent functionalization techniques [3-8]. An interesting approach for surface modification of CNTs involves the integration of the CNT with other functional components, which synergistically offers novel materials with potential applicability [4,8-10].

In terms of functionalization, SWCNT present high sensitivity to the experimental conditions, which may generate important changes in the pristine material, producing the modification of their intrinsic properties, for instance electrical conductivity and mechanical properties [11-13]. Therefore, mild surface-modification procedures that do not produce significant alterations in the SWCNT structure, are necessary for the design of new functional materials based on carbon nanotubes [14].

Some examples of non-covalent functionalization of SWCNT are based on the adsorption and wrapping of the SWCNT surface, through electrostatic interactions, $\pi-\pi$ stacking, hydrophobic forces or hydrogen bonds, with different types of conjugated polymers [13,15], metal nanoparticles [16], porphyrins, etc. [17-19].

Although, non-covalent functionalization of SWCNT does not produce significant damage in the carbon nanotubes structure, the weak interaction between the functional molecule and the CNTs, may not offer high stability, producing leaching and loss of the properties achieved after the functionalization [9]. In this context, incorporation of functional groups through covalent bonds in the CNTs side-wall or tips, results in functionalities on CNT with higher stability [20,21]. Covalent functionalization can be carried out employing oxidative conditions, promoting the generation of different surface 
oxygen groups, what is very useful for CNT processing [12,22,23]. Furthermore, other kind of functionalization based on different reactions such as fluorination, hydrogenation, esterification, alkylation, etc., has been employed in CNT covalent functionalization $[12,24,25]$. Unfortunately, most of the covalent functionalization procedures induce defects, which severely deteriorate the SWCNT structure and properties $[8,26]$. Therefore, development of non-damaging functionalization procedures of SWCNT, which may preserve as much as possible the properties of the pristine material, is an important challenge.

In the last decades, generation of highly reactive radicals under oxidative or reductive conditions by electrochemical methods (i.e., so-called electrografting methods), to anchor different functional molecules, such as diazonium salts, aliphatic and aromatic compounds, has emerged as a powerful methodology for covalent functionalization in different surfaces such as metals, oxides and carbon materials [8,27-29].

In previous studies done in our research group, MWCNTs and zeolite templated carbon (ZTC) were submitted to mild oxidative conditions in presence of different aminocontaining compounds producing functionalized materials with different redox processes and electroactivity in alkaline conditions [30,31]. This procedure promotes both covalent bonding and polymerization, thus resulting in strong interaction between both the MWCNT and the functionalizing compounds. In the previous study, 4-aminobenzyl phosphonic acid was used in which the phosphonic group is not directly bonded to the aromatic ring. The 4-aminobenzyl phosphonic acid had a low reactivity and did not produce a significant incorporation of phosphorus in the carbon nanotube. For this reason, the study of a molecule in which the phosphonic group is directly bonded to the aromatic ring is studied in the present work. Additionally, a systematic study of the effect of the oxidation potential has been done compared with the previous study. In this work, we apply cyclic voltammetry for the functionalization of SWCNT using 4-aminophenyl phosphonic acid (4-APPA), in order to achieve the co-doping of the SWCNT with N and $\mathrm{P}$ surface species, but avoiding important damage of the SWCNT. Interestingly, the degree of electrochemical modification of SWCNT surface can be easily controlled by selecting the electrochemical conditions. 


\section{Experimental}

\subsection{Materials}

Single-Wall Carbon nanotubes (SWCNT) with purity 99\% (1-4 nm of diameter) with 3-30 $\mu \mathrm{m}$ length were purchased to Cheap Tubes Inc (Cambridgeport, USA). Specific surface area, obtained by the Brunauer, Emmett and Teller (BET) method, is $587 \mathrm{~m}^{2} \cdot \mathrm{g}^{-1}$ and the total amount of surface oxygen, determined by temperature programmed desorption, is $277 \mu \mathrm{mol} \cdot \mathrm{g}^{-1}$ [32].

N, N-Dimethylformamide (DMF), extra pure, was provided by Scharlau and used as solvent to disperse the SWCNT. Sulphuric acid (98\%) analytical reagent to prepare the electrolyte, was obtained from VWR Chemicals. 4-Aminophenyl phosphonic acid (4-APPA, +98\%), used as modifier agent, was purchased from Tokyo Chemical Industry co (TCI). Potassium dihydrogen phosphate $\left(\mathrm{KH}_{2} \mathrm{PO}_{4}\right)$ and sodium sulfate $\left(\mathrm{Na}_{2} \mathrm{SO}_{4}\right)$ (99\%) were obtained from Merck. Dipotassium hydrogen phosphate tri-hydrate $\left(\mathrm{K}_{2} \mathrm{HPO}_{4} \cdot 3 \mathrm{H}_{2} \mathrm{O}\right)$ and Potassium Hydroxide $(\mathrm{KOH}, 85 \%)$ were purchased from VWR Chemicals, respectively. All the solutions were prepared using ultrapure water (18 MOhms $\cdot c m$, Purelab Ultra Elga equipment). The gases $\mathrm{N}_{2}(99.999 \%)$ and $\mathrm{H}_{2}(99.999 \%)$ were provided by Air Liquide.

\subsection{Surface functionalization with phosphorus and nitrogen species on SWCNT}

\subsection{1. $\mathrm{pH}$ for the point of zero-charge $\left(\mathrm{pH}_{\mathrm{PZC}}\right)$}

The determination of the $\mathrm{pH}_{\mathrm{PZC}}$ has been done using the method described in the literature [33]. Different amounts of $\operatorname{SWCNT}(0.05,0.1,0.5,1,5$ and $10 \% \mathrm{w} / \mathrm{w})$ were put in contact with ultrapure water. Samples were sonicated for 10 minutes and subsequently, were immersed in a thermostatic bath at $25^{\circ} \mathrm{C}$ and under stirring for 24 hours (equilibrium time). After this time, the samples were filtered and the $\mathrm{pH}$ of the solution obtained was measured. The $\mathrm{pH}_{\mathrm{PZC}}$ for the SWCNT was 6.3.

\subsubsection{Electrochemical modification with 4-Aminophenyl phosphonic acid (4-APPA)}

The working electrode for electrochemical modification was prepared using glassy carbon (GC) as support, modified with the SWCNT. $1 \mathrm{mg}$ of SWCNT was dispersed in DMF employing an ultrasonic cold-bath for 45 minutes, achieving a dispersion of $1 \mathrm{mg} \cdot \mathrm{mL}^{-1} \mathrm{SWCNTs}$. Prior to the deposition of SWCNT, glassy carbon electrode surface ( $3 \mathrm{~mm}$ diameter) was sanded with emery paper and polished using 1 and $0.05 \mu \mathrm{m}$ alumina 
slurries, then rinsed with ultrapure water. Afterwards, $5 \mu \mathrm{L}$ aliquot of the dispersion was dropped onto the glassy carbon surface and dried under an infrared lamp to remove the solvent. This procedure was repeated twice until completing $10 \mu \mathrm{L}$ of the carbon material suspension on the surface.

Electrochemical modification of SWCNT was performed using an Autolab PGSTAT 302 (Metrohm Netherlands) potentiostat, with a standard three-electrode cell configuration, in which the glassy carbon electrode modified with SWCNT was the working electrode (WE), a graphite rod was used as counter electrode (CE) and a reversible hydrogen electrode (RHE) introduced in the same electrolyte but without 4-APPA, was used as reference electrode (RE) (see Figure 1).
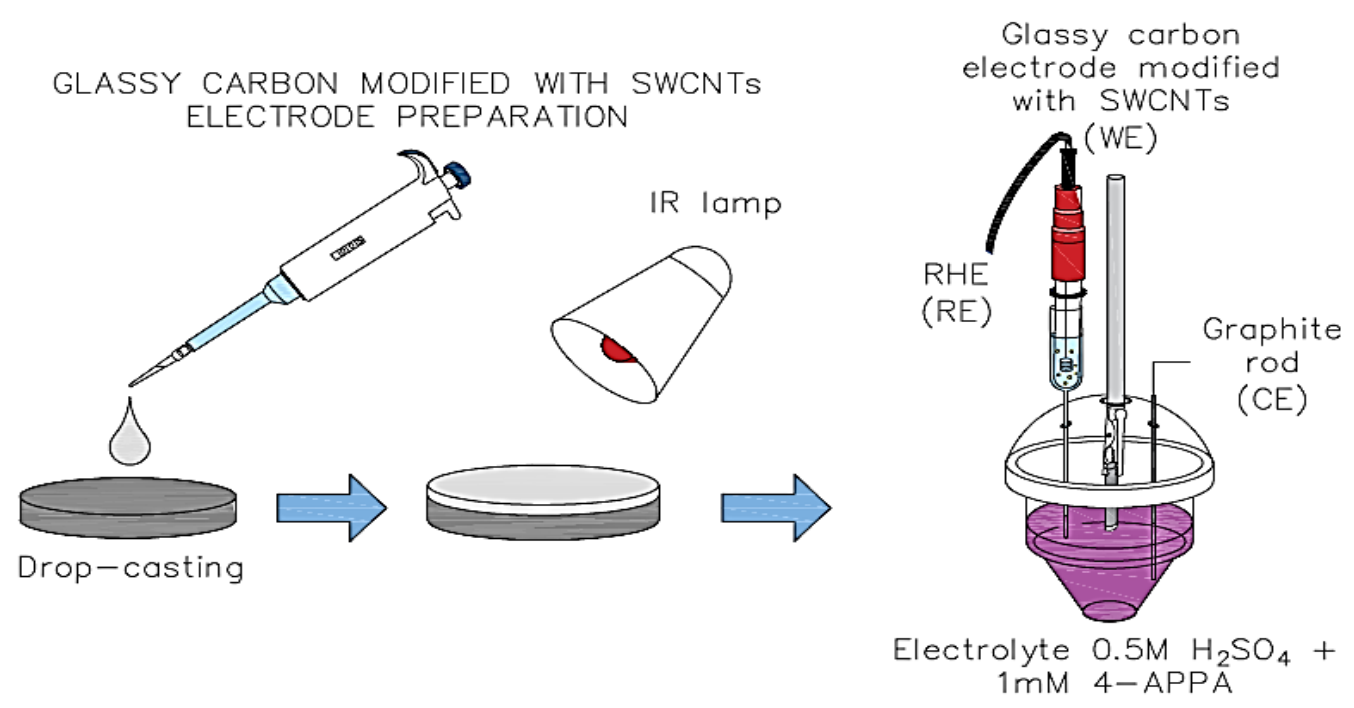

Figure 1. Experimental procedure for the electrochemical functionalization of SWCNT with 4-APPA.

Electrochemical modification was carried out by cyclic voltammetry in aqueous solution $0.5 \mathrm{M} \mathrm{H}_{2} \mathrm{SO}_{4}+1 \mathrm{mM}$ APPA in a deoxygenated cell by bubbling nitrogen. Modification of carbon material was achieved submitting the sample to 10 cycles at $10 \mathrm{mV} \cdot \mathrm{s}^{-1}$, in different potential windows, increasing the positive potential. After electrochemical treatment, carbon electrodes were washed with excess of water, removing the remaining electrolyte.

\subsubsection{Electrochemical characterization}

Electrochemical behavior of the SWCNT modified with 4-APPA was evaluated by cyclic voltammetry in different electrolytes (acid, neutral and alkaline electrolytes), 
employing a three electrode cell configuration, where, glassy carbon modified with SWCNT functionalized with 4-APPA, was the working electrode (WE), a graphite rod was the counter electrode (CE) and a reversible hydrogen electrode (RHE) introduced in the same electrolyte, was the reference electrode (RE). Potential range was fixed between 0 and $1 \mathrm{~V}$ at $50 \mathrm{mV} \cdot \mathrm{s}^{-1}$.

\subsection{Physicochemical characterization}

X-Ray photoelectron spectroscopy (XPS) was performed in a VG-Microtech Mutilab 3000 spectrometer using an $\mathrm{Al} \mathrm{K} \alpha$ radiation $(1253.6 \mathrm{eV})$. The deconvolution of the XPS peaks for $\mathrm{C} 1 \mathrm{~s}, \mathrm{O} 2 \mathrm{p}, \mathrm{P} 2 \mathrm{p}$ and N1s was done by least squares fitting using GaussianLorentzian curves, while a Shirley line was used for the background determination. The P2p spectra have been analyzed considering the spin-orbit splitting into P2p3/2 and $\mathrm{P} 2 \mathrm{p} 1 / 2$ with a 2:1 peak area ratio and an energy separation of $0.87 \mathrm{eV}$.

Transmission electron microscopic measurements (TEM) were carried out using JEOL TEM, JEM-2010 model, INCA Energy TEM 100 model, and GATAN acquisition camera.

Raman spectra were collected with a Jasco NRS-5100 spectrometer with a focal distance of $300 \mathrm{~mm}$. A solid-state laser $(532 \mathrm{~nm})$ with $3.9 \mathrm{~mW}$ was used. The spectra were acquired for $120 \mathrm{~s}$. The Raman set-up was coupled to a microscope with an objective of 20 magnifications (MPLFLN 20x). Previous to the analysis, calibration of the spectrometer was performed with a Si slice $\left(521 \pm 2 \mathrm{~cm}^{-1}\right)$, checking the shifting in the line at $520 \mathrm{~cm}^{-1}$ and correcting the base line to eliminate the effect of the fluorescence.

\section{Results and discussion}

\subsection{Electrochemical functionalization of SWCNT in acid medium with phosphorus and} nitrogen species

\subsubsection{Electrochemical oxidation of SWCNT in acid medium in presence of 4-APPA}

In order to establish the most adequate conditions for electrochemical functionalization of SWCNT surfaces with phosphorus and nitrogen species employing 4-APPA, the upper potential limit was step-wise opened from 0.8 to $1.8 \mathrm{~V}$, as can be observed in Fig. 2-A. 

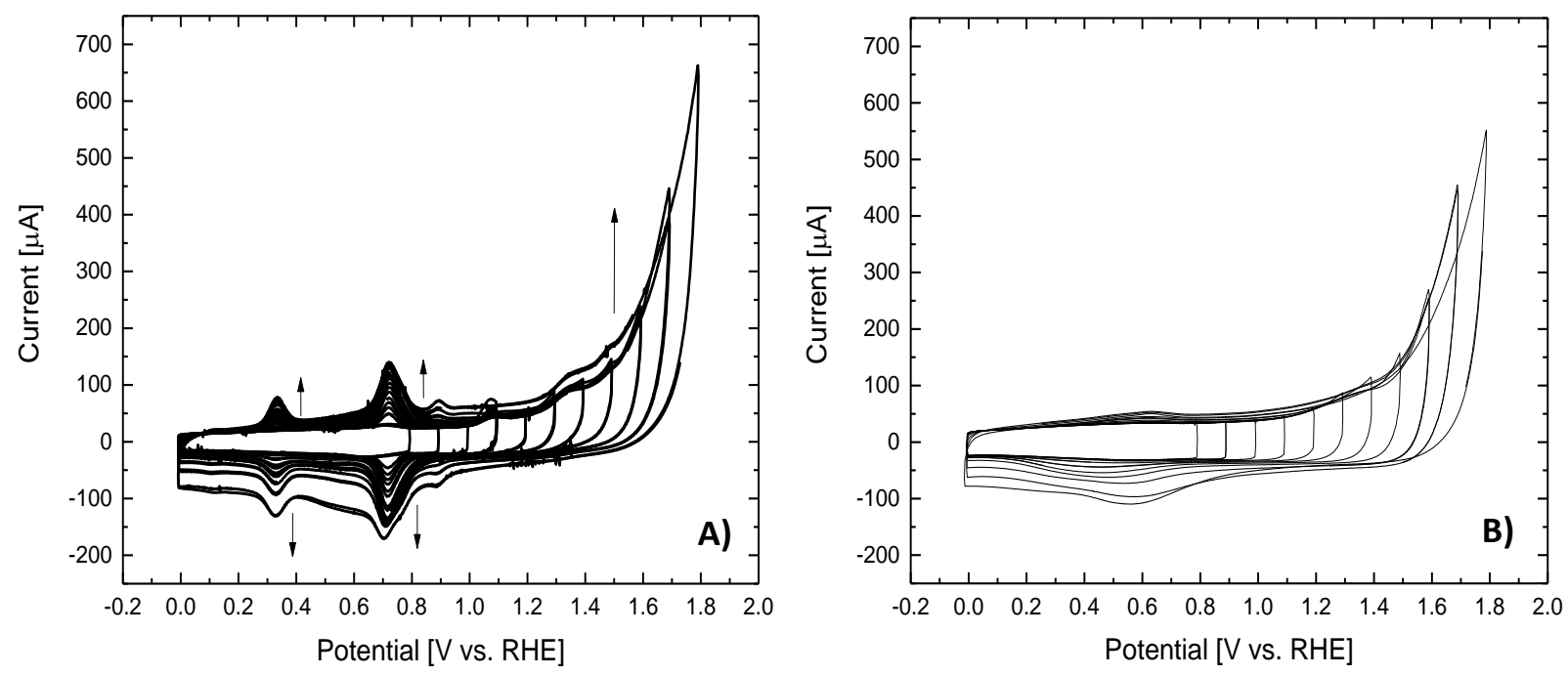

Figure 2. Cyclic voltammograms during the first cycle of the open step-wise potential window for: A) SWCNT in $0.5 \mathrm{M} \mathrm{H}_{2} \mathrm{SO}_{4}+1 \mathrm{mM}$ 4-APPA and B) SWCNT in $0.5 \mathrm{M}$ $\mathrm{H}_{2} \mathrm{SO}_{4}$ at $50 \mathrm{mV} \cdot \mathrm{s}^{-1}$.

In presence of 4-APPA in the electrolyte, a highly reversible process appears in the voltammograms at $0.68 \mathrm{~V}$, when the upper potential limit reaches values of $0.8 \mathrm{~V}$. The intensity of this redox process increases with the number of cycles, as can be observed in Fig. 2-A. Moreover, when the positive potential increases, irreversible anodic waves at around $1.1 \mathrm{~V}$ and $1.4 \mathrm{~V}$ appear, that can be associated with the oxidation of 4-APPA, together with an increase in current at higher potentials similar to what is observed in the voltammogram of the SWCNT in absence of 4-APPA (Fig. 2-B). However, the current is higher in presence of 4-APPA. Additionally, the increase in the double-layer capacitance and the development of an additional redox process at $0.31 \mathrm{~V}$ are also observed. This redox process increases with the number of cycles.

Considering the previous electrochemical step-wise potential study in SWCNT, different upper potential limits were chosen. Surface functionalization of SWCNT has been studied using different electrode samples at each potential. Fig. 3 shows the voltammograms obtained for the different positive potentials studied in absence and in presence of 4-APPA in the electrolyte. For all the potentials evaluated, the voltammograms for the SWCNT modified electrodes in $0.5 \mathrm{M} \mathrm{H}_{2} \mathrm{SO}_{4}$ in absence of 4-APPA (black line in Fig. 3), present the development of a broad redox process at around $0.5 \mathrm{~V}$ that corresponds to the formation of oxygen functionalities [34], as consequence of the electrooxidation of SWCNT. This redox process increases with the positive potential limit as well as its irreversibility (Fig. 3-E). 
Once the 4-APPA is incorporated in the electrolyte (red lines CVs in Fig. 3), an overoxidation current at higher potential is observed for all the upper potentials studied, related with the contribution of 4-APPA to the oxidation current. Fig 3-A shows the voltammograms when the upper potential limit is $1.0 \mathrm{~V}$. It is clear the appearance of a reversible redox process at $0.71 \mathrm{~V}$ (peak $\mathrm{C}$ ) that increases with the number of cycles. When the upper potential limit is $1.2 \mathrm{~V}$, an irreversible oxidation peak at $1.1 \mathrm{~V}$ (See Fig. 3-B) is clearly observed during the first cycle that decreases with the number of cycles. Moreover, the current of the first redox process at $0.71 \mathrm{~V}$ increases with the number of cycles, in comparison with Fig. 3-A. At the same time, other redox processes at 0.33 (peak B) and 0.53 (peak D) are also observed. Further polarization above $1.2 \mathrm{~V}$ (Fig. 3-C and $3-\mathrm{D})$, produces the increase in the current of these redox processes and their relative current depends on the potential. The appearance of these processes can be related with the formation of electroactive species, such as oxidative radicals, dimers or oligomers on the SWCNT surface. 

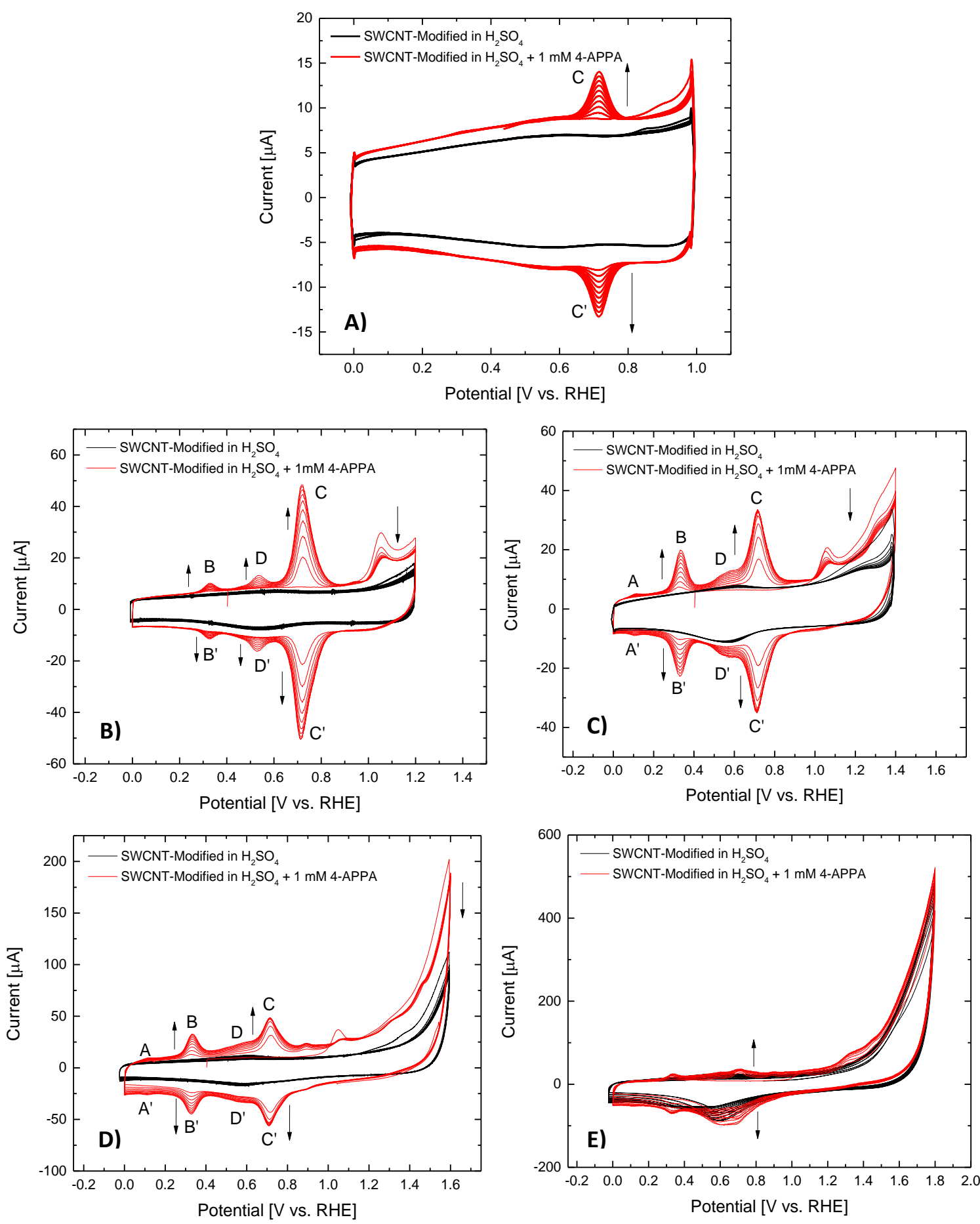

Figure 3. Cyclic voltammograms obtained during 10 cycles for a SWCNT electrode in $0.5 \mathrm{M} \mathrm{H}_{2} \mathrm{SO}_{4}$ (Black lines) and $0.5 \mathrm{M} \mathrm{H}_{2} \mathrm{SO}_{4}+1 \mathrm{mM} 4$-APPA (Red lines) at $10 \mathrm{mV} \cdot \mathrm{s}^{-1}$ under $\mathrm{N}_{2}$ atmosphere at different positive potential limits: A) $\left.1.0 \mathrm{~V}, \mathrm{~B}\right) 1.2 \mathrm{~V}$, C) $1.4 \mathrm{~V}$, D) $1.6 \mathrm{~V}$ and E) $1.8 \mathrm{~V}$.

\subsubsection{Electrochemical characterization of SWCNT functionalized with $P$ and $N$}

Evidence of the functionalization with $\mathrm{P}$ and $\mathrm{N}$ species in the SWCNT was verified by $\mathrm{CV}$ in acid media without presence of the 4-APPA in the solution. Fig. 4 shows the voltammograms of the functionalized SWCNTs prepared at different potentials as 
explained in the previous section (see Fig. 3). The voltammograms of the SWCNT submitted to the same polarization conditions in absence of 4-APPA are also presented for comparison purposes (Black lines).
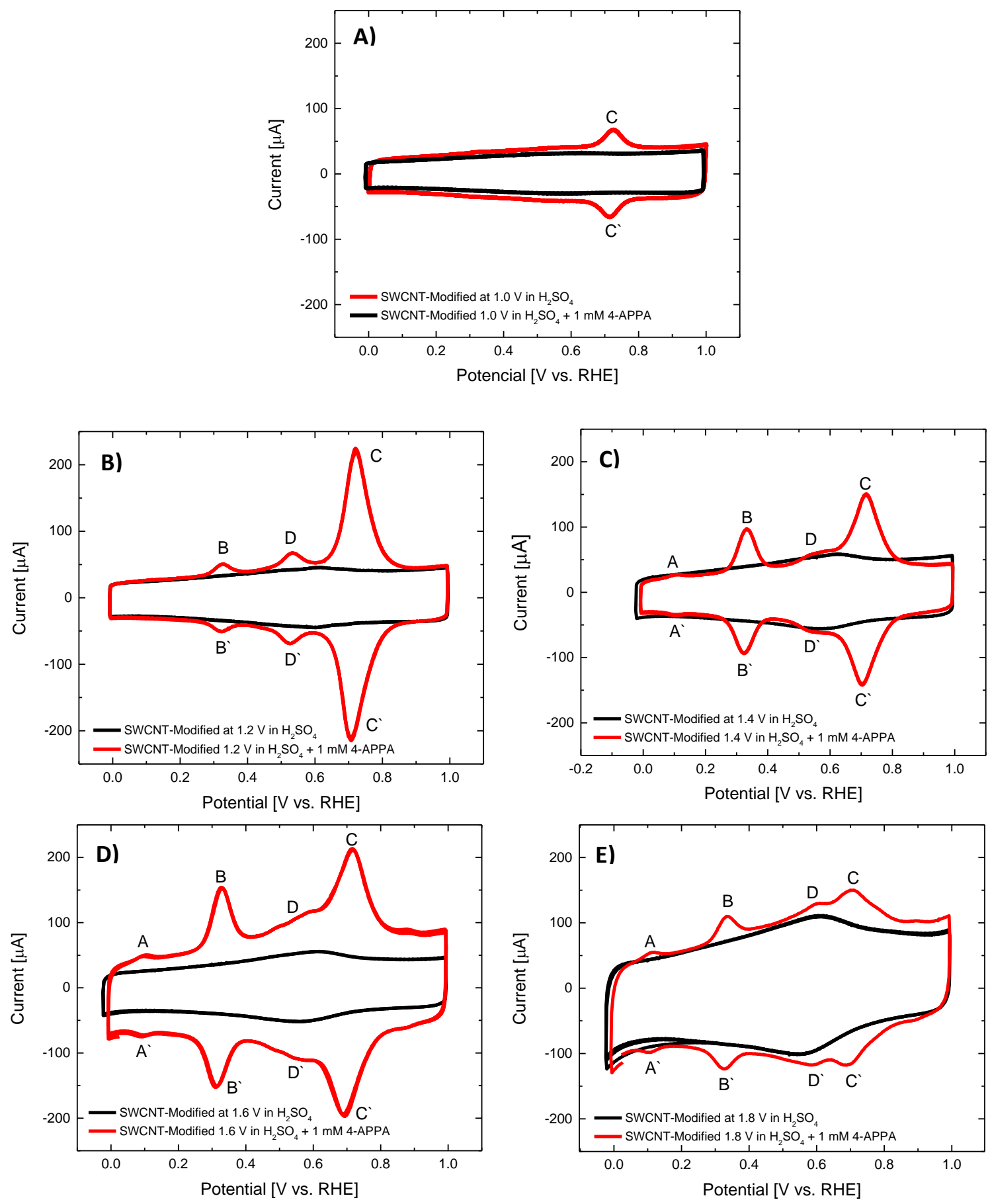

Figure 4. Steady state voltammograms for the modified SWCNTs in absence (black line) and presence (red line) of 4-APPA at different potential: A) $1.0 \mathrm{~V}, \mathrm{~B}) 1.2 \mathrm{~V}$, C) $1.4 \mathrm{~V}$, D) $1.6 \mathrm{~V}$ and E) $1.8 \mathrm{~V} .0 .5 \mathrm{M} \mathrm{H}_{2} \mathrm{SO}_{4}, 50 \mathrm{mV} \cdot \mathrm{s}^{-1}$ 
After the electrochemical modification process, the electrode was removed from the 4-APPA containing solution, washed with ultrapure water and introduced in a $0.5 \mathrm{M}$ $\mathrm{H}_{2} \mathrm{SO}_{4}$ solution in absence of 4-APPA to carry out the experiments in Fig. 4. In terms of the different electrochemical processes observed in acidic conditions in the SWCNT after modification, all the oxidation/reduction processes induced in the CNTs present high stability with cycling between 0 and $1 \mathrm{~V}$, suggesting a good anchoring of the electroactive species on the CNT surface. Moreover, the modified SWCNTs show an outstanding increase in the current density, corresponding to an increase in the stored-charge, which is proportional to the increase of the upper potential limit until $1.6 \mathrm{~V}$. The values of storedcharge measured after modification at potentials higher than $1.2 \mathrm{~V}$, is above $200 \%$ of the initial value of the pristine SWCNT (Table 1).

Table 1. Electrochemical parameters for the different electrochemical processes in SWCNT modified with 4-APPA at different potentials. All the values were determined for the $\mathrm{CVs}$ at $\mathrm{v}_{\mathrm{scan}}=50 \mathrm{mV} \cdot \mathrm{s}^{-1}$.

\begin{tabular}{|c|c|c|c|c|c|c|c|c|c|c|c|}
\hline \multirow{2}{*}{$\begin{array}{c}\text { Upper } \\
\text { potential } \\
\text { limit } \\
\text { [V vs. } \\
\text { RHE] }\end{array}$} & \multicolumn{3}{|c|}{$\begin{array}{c}\text { Total stored-charge } \\
{[\mu \mathrm{C}]^{*}}\end{array}$} & \multirow{2}{*}{$\begin{array}{c}\Delta \mathbf{E}^{\mathbf{A}} \\
{[\mathbf{m V}]}\end{array}$} & \multirow{2}{*}{$\begin{array}{c}\Delta \mathbf{E}^{\mathbf{B}} \\
{[\mathrm{mV}]}\end{array}$} & \multirow{2}{*}{$\begin{array}{c}\Delta \mathrm{E}^{\mathrm{C}} \\
{[\mathrm{mV}]}\end{array}$} & \multirow{2}{*}{$\begin{array}{c}\Delta \mathbf{E}^{\mathrm{D}} \\
{[\mathrm{mV}]}\end{array}$} & \multirow[b]{2}{*}{$\mathbf{I}^{\mathrm{ox}} / \mathbf{I}^{\mathrm{red}}{ }_{A}$} & \multirow[b]{2}{*}{$\mathbf{I}^{\mathrm{ox}} / \mathbf{I}^{\mathrm{red}}{ }_{\mathrm{B}}$} & \multirow[b]{2}{*}{$\mathbf{I}^{\mathrm{ox}} / \mathbf{I}^{\mathrm{red}} \mathrm{C}$} & \multirow[b]{2}{*}{$\mathbf{I}^{\text {ox }} / \mathbf{I}^{\text {red }} \mathrm{D}$} \\
\hline & Acid & PBS & Alkaline & & & & & & & & \\
\hline Pristine & 612 & 427 & 460 & -- & -- & -- & -- & -- & -- & -- & -- \\
\hline 1.0 & 736 & 600 & 660 & -- & 3 & 10 & -- & -- & 0.95 & 1 & -- \\
\hline 1.2 & 1136 & 570 & 530 & -- & 3 & 14 & 7 & -- & 0.99 & 1 & 0.99 \\
\hline 1.4 & 1076 & 1260 & 1030 & 1 & 8 & 14 & 10 & 0.79 & 1 & 1 & 0.97 \\
\hline 1.6 & 1869 & 1260 & 1130 & 10 & 15 & 23 & 18 & 0.70 & 1 & 1 & 1 \\
\hline 1.8 & 1849 & 1510 & 1490 & 15 & 9 & 21 & 11 & 0.56 & 0.88 & 1 & 1 \\
\hline
\end{tabular}

*Stored-charge was determined in $0.5 \mathrm{M} \mathrm{H}_{2} \mathrm{SO}_{4}, 0.1 \mathrm{M}$ PBS $(\mathrm{pH}=7.2)$ and $0.1 \mathrm{M} \mathrm{KOH}$.

The electrochemical study with the scan rate of the modified SWCNT electrodes can be observed in Fig. S1 in acid media. In all cases, linear-dependence behavior of the oxidation and reduction currents with the scan rate is observed for all the redox processes formed during the functionalization (See Fig. S2), indicating that all of them are surface processes [35]. Values of peak potential separation for all the redox processes are lower than $25 \mathrm{mV}$ and current ratio $\mathrm{I}_{\mathrm{ox}} / \mathrm{I}_{\mathrm{red}}$ are close to one for processes $\mathrm{B}, \mathrm{C}$ and $\mathrm{D}$, suggesting that the electroactive functionalities incorporated onto the SWCNT present a highly 
reversible behavior (see Table 1). When the oxidation potential is $1.8 \mathrm{~V}$, a decrease in the redox processes is clearly observed in the voltammogram (Fig. 4-E), which can be a consequence of an over oxidation that can produce oxidative degradation of the species present on the surface.

The obtained results could be explained considering aniline-based compounds polymerization although covalent bonding with the SWCNT cannot be discarded. It is well-known that aniline-based compounds oxidize with the formation of radicals that can react giving polyaniline-type products [36-38]. The redox processes observed with a high reversibility are in agreement with the formation of polyaniline-based oligomers. In polyaniline, redox processes, related with the change of the oxidation states from leucoemeraldine to emeraldine and emeraldine to pernigraniline in the polymer chain, appear at around 0.3 and $0.7 \mathrm{~V}$ vs. RHE in acid conditions, respectively [39,40]. However, the high reversibility and symmetry of the redox processes suggest that covalently bound redox species may also exist. In fact, another possibility that has to be considered is that the amine radical could also react with the SWCNT, promoting the formation of N-C bonds and producing a covalent attachment of the 4-APPA molecule on the carbon nanotubes surface. Polymerization could further proceed through these covalently bonded species. However, electroactivity for the 4-APPA molecule covalently attached to the SWCNT surface, if it occurs, should not result in well-defined redox processes as observed in Fig. 4 due to the expected energy heterogeneity arisen from the different sites of the SWCNT where the attachment may occur (i.e., the tip or the wall of the CNT). Nevertheless, these interesting redox processes should be subject of further research, although it cannot be discarded that the strong interaction between the polymer and the SWCNT may be the responsible for the high reversibility observed due to an enhanced electron transfer.

The first step in the polymerization of 4-APPA is the adsorption of the monomer on the SWCNT. At the experimental conditions used $\left(0.5 \mathrm{M} \mathrm{H}_{2} \mathrm{SO}_{4}\right)$ the monomer will be fully protonated forming phosphonic acid and anilinium cations. Since the SWCNT have a low oxygen content and have not been subjected to any oxidation treatment $\left(\mathrm{pH}_{\mathrm{pzc}}=6.3\right)$, at the $\mathrm{pH}$ of the experiments, the surface will be positively charged. Consequently, the adsorption of the 4-APPA molecule will not occur through the protonated amine group due to repulsive electrostatic interactions and dispersive interactions (i.e., $\pi-\pi$ interactions) would be the main adsorption mechanism $[41,42]$. This 
means that although the surface coverage by 4-APPA will not be high, the adsorption of the molecules will mainly occur parallel to the SWCNT surface. Thus, at oxidation conditions, the 4-APPA radicals could be formed at the surface of the SWCNT and react with other adsorbed (or covalently bonded) molecules forming the oligomers with the expected electroactivity from the $\mathrm{N}$ species. This possibility will be further reinforced with the characterization of the obtained materials presented in the next sections. It must be noted that 4-APPA oligomerization is not observed on platinum electrodes, in which polyaniline growth is straightforward, being necessary the addition of aniline to produce co-polimerization [43]. This suggests that monomer adsorption and orientation on the electrode determine the polymerization reaction.

Electrochemical properties of surface functionalities onto the SWCNT have an important dependence with the $\mathrm{pH}$. This can be observed in Fig. 5, for SWCNT electrochemically modified at 1.2 and $1.4 \mathrm{~V}$ in different electrolytes. Voltammograms for SWCNT modified at other potentials can be observed in Fig S3. In general, with increasing the $\mathrm{pH}$, the current of the processes decreases (or even disappears) and the peak separation increases. Thus, at neutral $\mathrm{pH}(0.1 \mathrm{M}$ PBS solution at $\mathrm{pH}=7.2)$, redox processes present an increase in the peak separation or even a loss of electroactivity. At alkaline $\mathrm{pH}$, the reduction of the electrochemical activity of the redox processes is remarkable and only redox process $\mathrm{C}$ is observed. Increase in the peak separation of the electrochemical processes can be a result of the loss of reversibility of the surface redox processes with the increase of $\mathrm{pH}[44,45]$. This behavior with the $\mathrm{pH}$ is in agreement with polyaniline-type products that loss their electroactivity with the increase of the $\mathrm{pH}$.
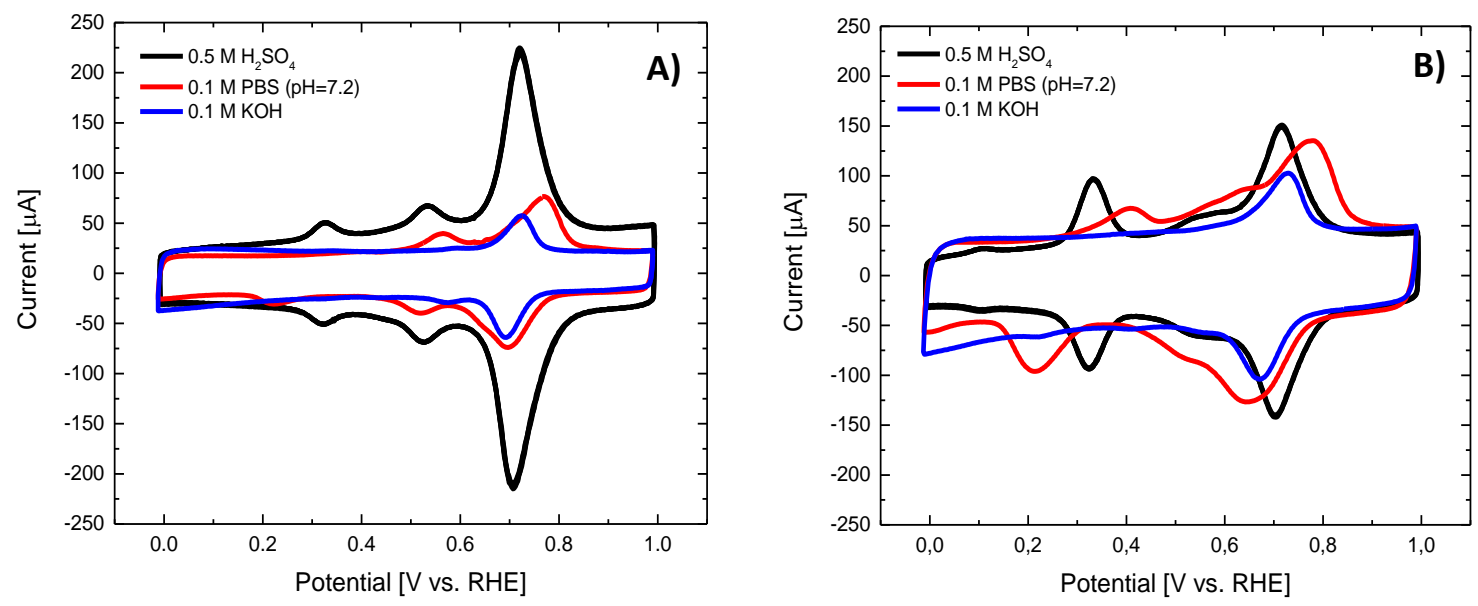

Figure 5. Steady state voltammograms for the modified SWCNTs with 4-APPA at: A) $1.2 \mathrm{~V}$ and $\mathrm{B}) 1.4 \mathrm{~V}$ in $0.5 \mathrm{M} \mathrm{H}_{2} \mathrm{SO}_{4}$ (Black lines), 0.1 M PBS ( $\mathrm{pH}=7.2$-Red lines) and $0.1 \mathrm{M} \mathrm{KOH}$ (Blue lines) at $50 \mathrm{mV} \cdot \mathrm{s}^{-1}$ under $\mathrm{N}_{2}$ atmosphere. 
3.2.Morphological characterization of SWCNT modified electrochemically with P and $N$ species

Fig. 6 shows the TEM images for pristine SWCNT and the same carbon nanotubes after electrochemical modification with 4-APPA at the different anodic potentials.
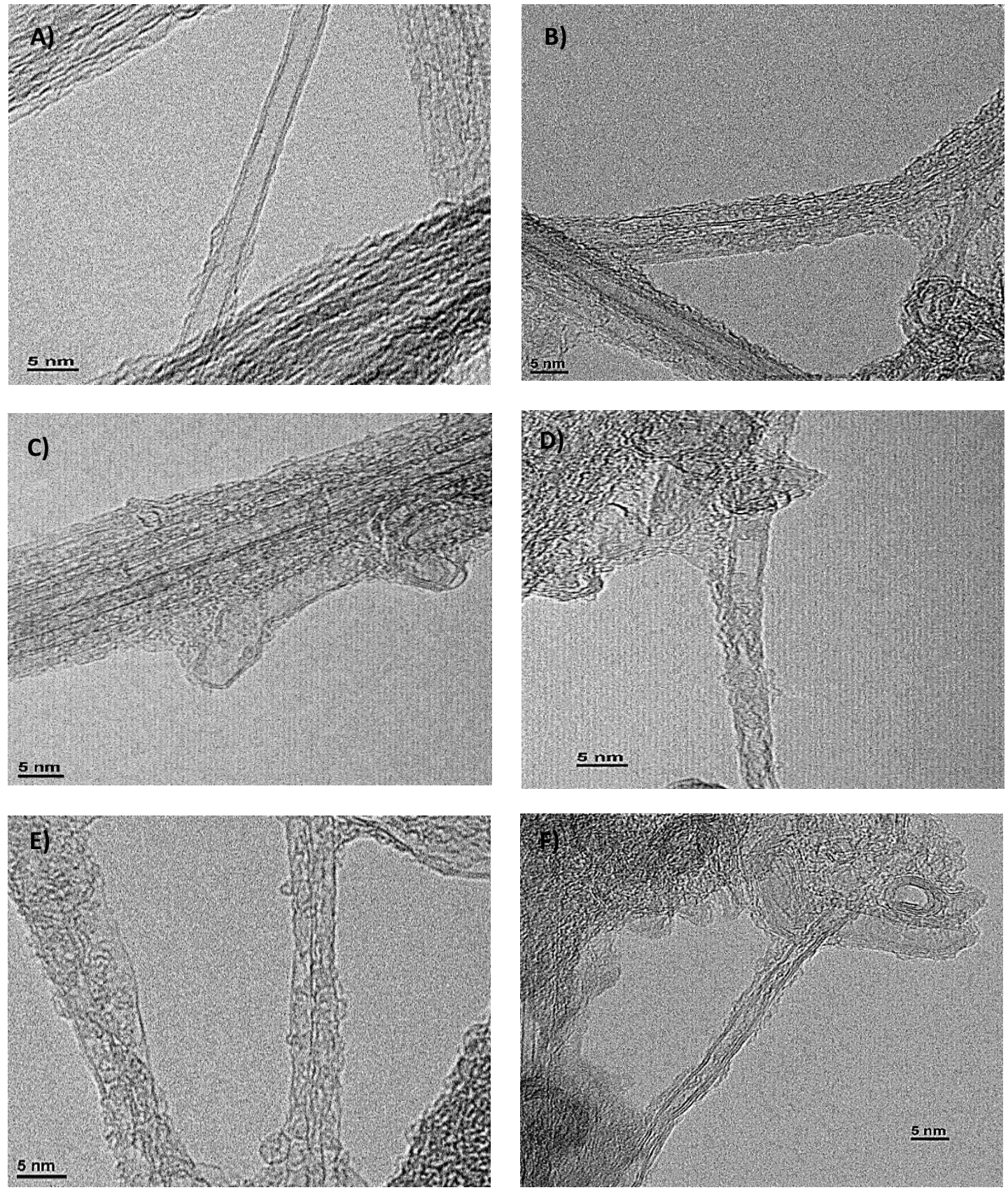

Figure 6. HR-TEM micrographs for SWCNT electrochemical modified with 4-APPA at: A) Pristine, B) $1.0 \mathrm{~V}$, C) $1.2 \mathrm{~V}$, D) $1.4 \mathrm{~V}$, E) $1.6 \mathrm{~V}$ and F) $1.8 \mathrm{~V}$ vs. RHE.

SWCNT presents the typical tubular structure and is formed by one-two layers of rolled-graphene layers (Fig. 6-A). Once SWCNT are modified with 4-APPA, a deposited material on the SWCNT is clearly observed, which morphology seems to be dependent on the applied potential. This is a direct proof for the polymerization of 4-APPA on the 
SWCNT. The formed oligomers are wrapping the CNT surface and when the applied potential is 1 or $1.2 \mathrm{~V}$, uniform layers of the oligomers can be clearly observed, what is in agreement with the proposed reaction mechanism (Fig. 6-B and C). However, at higher potentials, the deposited material has not such homogeneity and even discontinuous or not linear chains can be observed. This can be due to the strong oxidation of the polymer or to the creation of oxygen functional groups on the CNT that modify the orientation of the 4-APPA molecules, producing less ordered and shorter polymer chains (Fig. 6-D, E and F).

Interestingly, non-important structural changes, such as broken-walls of SWCNTs can be observed, suggesting that, despite the high oxidative conditions used, destruction and morphological changes on the SWCNTs shape are not very important, being the oxidation mainly focused on the 4-APPA polymerization.

\subsection{XPS analysis of $P$ and $N$ species on electrochemically modified SWCNT}

The degree of incorporation of $\mathrm{O}, \mathrm{N}$ and $\mathrm{P}$ species, and the chemical nature of the different surface functionalities incorporated on the SWCNT were studied by XPS. Table 2 summarizes the amount of $\mathrm{O}, \mathrm{N}$ and $\mathrm{P}$ incorporated in the SWCNT during the electrochemical modification.

Table 2. Chemical composition obtained from XPS of the electrochemical modified SWCNT with 4-APPA.

\begin{tabular}{ccccc}
$\begin{array}{c}\text { Applied } \\
\text { potential [V } \\
\text { vs. RHE] }\end{array}$ & $\begin{array}{c}\% \mathbf{O} \\
\text { (at) }\end{array}$ & $\begin{array}{c}\text { (at) } \\
\text { (at) }\end{array}$ & $\mathbf{N} / \mathbf{P}^{*}$ \\
\hline Pristine & 3.13 & 0.37 & 0.00 & -- \\
$\mathbf{1 . 2}$ & 3.93 & 0.60 & 0.15 & 1.5 \\
$\mathbf{1 . 4}$ & 5.03 & 0.83 & 0.24 & 1.9 \\
$\mathbf{1 . 6}$ & 6.81 & 1.24 & 0.5 & 1.7 \\
$\mathbf{1 . 8}$ & 12.66 & 1.58 & 0.44 & 2.8 \\
\hline
\end{tabular}

*The N content of the pristine SWCNT has been subtracted for the calculation.

The electrochemical modification at $1 \mathrm{~V}$ (Fig. 4-A) shows redox processes in the sample, suggesting the incorporation of functionalities on the CNT surface. However, the low amount of $\mathrm{N}$ and $\mathrm{P}$ detected, close to the detection limit of the technique, makes 
impossible a proper quantification of these species in the modified SWCNT. This indicates that the electrochemical characterization has better sensitivity to surface modification than other techniques. For this reason, the data at $1 \mathrm{~V}$ are not included in the table. The results obtained for higher potentials show that the nitrogen content increases with the upper positive potential limit. The content of phosphorus also increases with the potential; however, at $1.8 \mathrm{~V}$ the amount of phosphorus decreases, probably due to the oxidation of the phosphonic groups to phosphoric groups that can be further hydrolyzed (See Table 2). The ratio N/P is between 1.5 and 1.9 for all the studied potentials except for $1.8 \mathrm{~V}$, indicating that the incorporation of the 4-APPA maintains both functional groups although some phosphonic groups are lost at these conditions. The oxygen content does not experience a strong increase until the highest potentials are reached and at which less ordered and shorter polymer chains are observed. This means that at this potential, a strong oxidation of the polymer and also of the SWCNT may occur.

Fig. 7 presents the XPS N1s spectra for the SWCNT modified at different upper potential limits, showing different species depending on the applied potential. The region between 398.5-and 400.1 eV can be assigned to neutral amines and imines species, respectively, generated during the oxidation of 4-APPA which are also observed in PANI, and are in agreement with the formation of oligomer/polymeric chains [40,46,47]. A third peak at around $402 \mathrm{eV}$ is also observed in all the potentials. This peak can be associated with more oxidized nitrogen species $[47,48]$. These oxidized nitrogen species increase significantly in the SWCNT modified at $1.8 \mathrm{~V}$, in agreement with what has been observed in other amine-containing molecules, electrochemically attached on different materials surfaces $[49,50]$. 

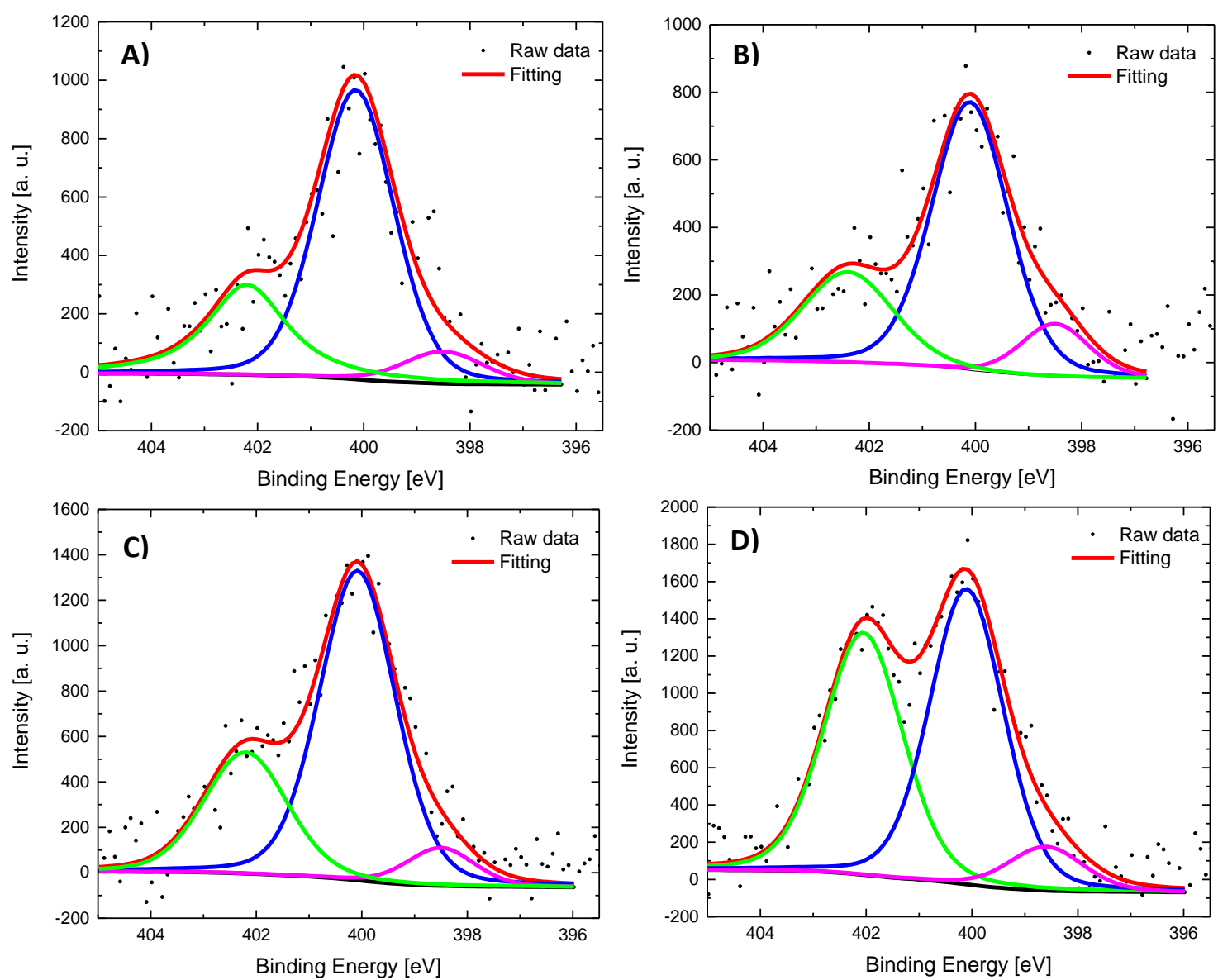

Figure 7. N1s XPS spectra for SWCNT electrochemical modified with 4-APPA at different oxidation potentials: A) $1.2 \mathrm{~V}$, B) $1.4 \mathrm{~V}$, C) $1.6 \mathrm{~V}$ and D) $1.8 \mathrm{~V}$ vs. RHE.

Regarding the P2p spectra in Fig. 8, two asymmetric doublets are observed (the XPS for the sample prepared at $1.2 \mathrm{~V}$ is not deconvoluted because of the low amount of $\mathrm{P}$, making the spectrum very noisy). The first contribution at $132.6 \mathrm{eV}$ can be associated with the binding energy of C-P-O species [51,52], in agreement with the presence of the phosphonic group [53,54]. A second contribution at $133.3 \mathrm{eV}$ can be related to C-O-P species that are formed as consequence of the oxidation of the phosphonic group to phosphoric group [51,52,55,56]. 

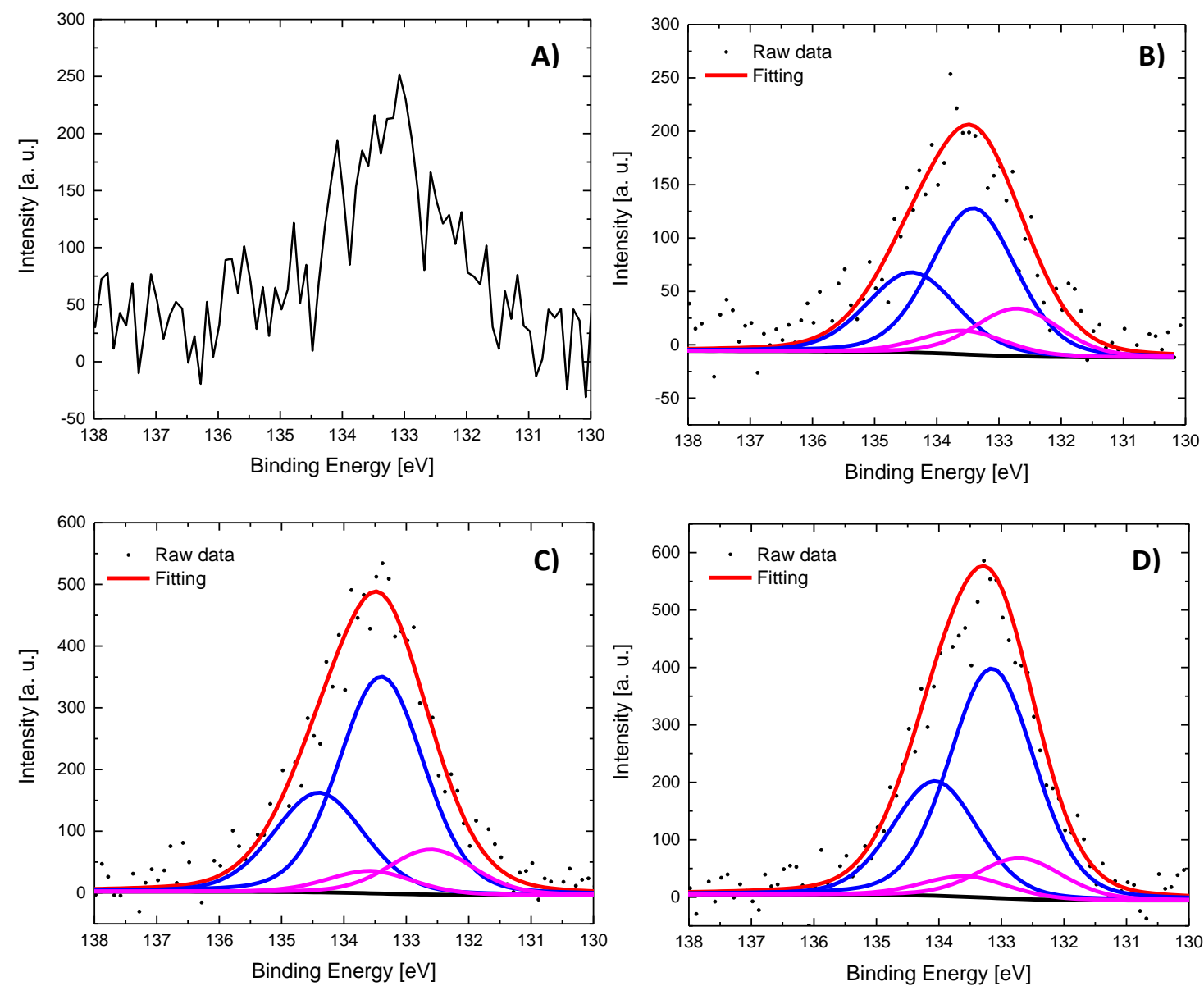

Figure 8. P2p XPS spectra for SWCNT electrochemical modified with 4-APPA at different oxidation potentials: A) $1.2 \mathrm{~V}$, B) $1.4 \mathrm{~V}$, C) $1.6 \mathrm{~V}$ and D) $1.8 \mathrm{~V}$ vs. RHE.

Table 3 presents the atomic percentage for each $\mathrm{N}$ and $\mathrm{P}$ species determined by XPS for the modified SWCNTs. In the case of nitrogen important changes can be observed at $1.8 \mathrm{~V}$ where nitrogen species corresponding with neutral species, decrease with the corresponding increase in oxidized nitrogen species. This is especially remarkable at the highest potential in which different nitrogen species compared to polyaniline [35] must be present at the surface. It must be noted that oxidized nitrogen is, in all the cases, higher than for phosphonic acid ring-substituted polyanilines prepared via direct chemical phosphonation [57]. Interestingly, phosphorus species associated with the phosphonic moieties present a constant value until a positive potential limit of $1.4 \mathrm{~V}$ and its contribution decreases at 1.6 and $1.8 \mathrm{~V}$. Table 3 shows that the main P-species corresponds to phosphoric acid functionality (C-O-P) as consequence of the oxidation of the phosphonic group. 
Table 3. Distribution of N1s contributions for SWCNT electrochemically modified with 4-APPA at different potentials.

\begin{tabular}{|c|c|c|c|c|}
\hline $\begin{array}{c}\text { Potential } \\
\text { applied } \\
\text { [V vs. } \\
\text { RHE] }\end{array}$ & $\begin{array}{c}\% \text { Neutral } N \\
\text { species }(398.5 \\
\text { and } 400.1 \mathrm{eV})\end{array}$ & $\begin{array}{c}\% \\
\text { Oxidized } \\
\text { nitrogen } \\
(402.2 \mathrm{eV})\end{array}$ & $\begin{array}{c}\text { C-O-P } \\
(133.3 \mathrm{eV})\end{array}$ & $\begin{array}{c}\text { C-P-O } \\
(132.6 \mathrm{eV})\end{array}$ \\
\hline 1.2 & 73 & 27 & 71 & 29 \\
\hline 1.4 & 75 & 25 & 75 & 25 \\
\hline 1.6 & 72 & 28 & 83 & 17 \\
\hline 1.8 & 57 & 43 & 85 & 15 \\
\hline
\end{tabular}

*All the percentages correspond with the total amount of each N1s and P2p determined.

\subsection{Raman spectroscopy of SWCNT electrochemically modified with 4-APPA}

Raman spectroscopy was employed to analyze the structural and physicochemical changes produced by the electrochemical modification of the SWCNT with 4-APPA. Raman spectra in Fig. 9-A for pristine SWCNT and electrochemically modified with 4APPA, present mainly two contributions associated with $\mathrm{C}-\mathrm{C}$ vibration, the $\mathrm{G}\left(1585 \mathrm{~cm}^{-}\right.$ ${ }^{1}$ ) and $\mathrm{D}\left(1350 \mathrm{~cm}^{-1}\right)$ bands, corresponding to an ideal graphitic lattice vibration mode and with a disorder-induced band, respectively [58-60].
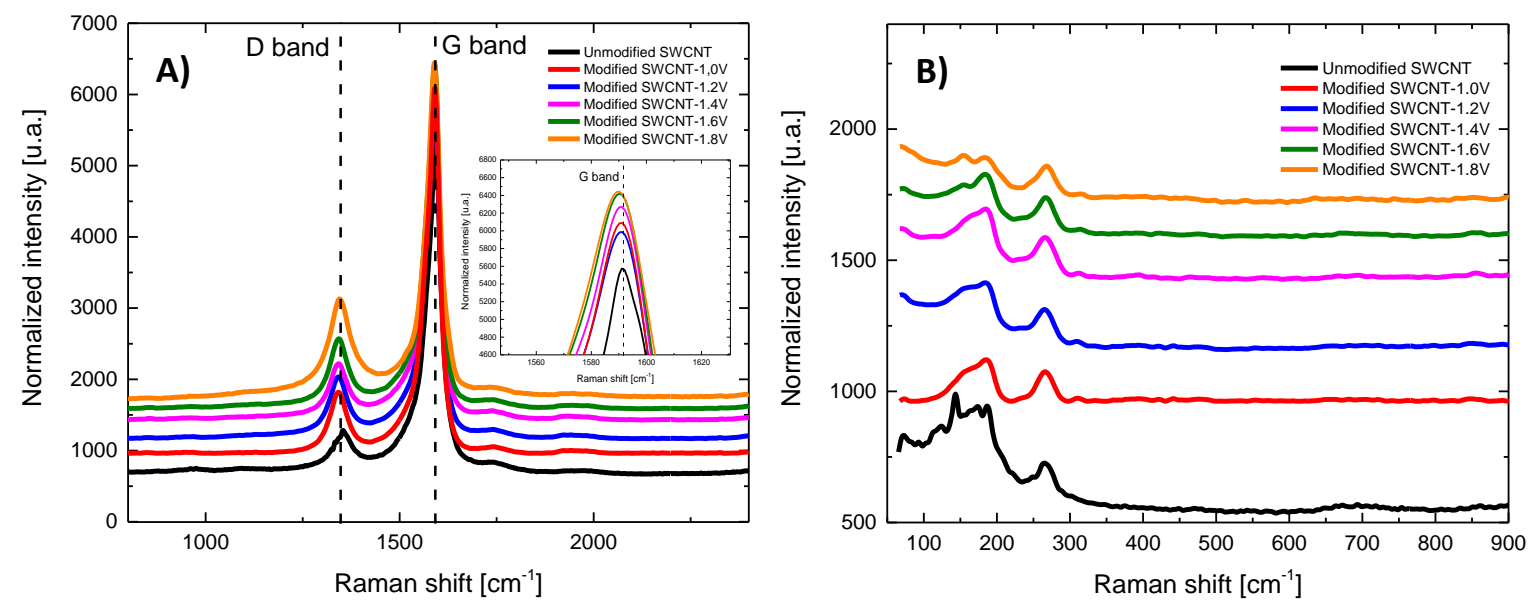

Figure 9. Raman spectra of SWCNT electrochemical modified with 4-APPA at different potentials: A) D and G band region, and B) RBM region of SWCNT.

It can be observed a similar Raman spectrum for all the modified SWCNT. However, the electrochemical modification causes an increase in the ratio of the relative intensities 
for these two bands $\left(\mathrm{I}^{\mathrm{D} / \mathrm{I}^{\mathrm{G}}}\right)$, as can be observed in Fig. 10. Moreover, the intensity and the position of the G-Band change with the functionalization from $1592 \mathrm{~cm}^{-1}$ for the pristine SWCNTs to $1589 \mathrm{~cm}^{-1}$ for the functionalized SWCNTs at $1.8 \mathrm{~V}$. This could indicate changes in the electronic structure, in doping or in the resonance conditions of the SWCNTs contributing to G-Band [61]. However, this shift is especially important for the highest potentials used at which the changes in the morphology are clearly observed by TEM. These changes are in agreement with the reaction with 4-APPA species, the interaction of polymer chains on the CNT and the defects induced in the CNT by electrooxidation.

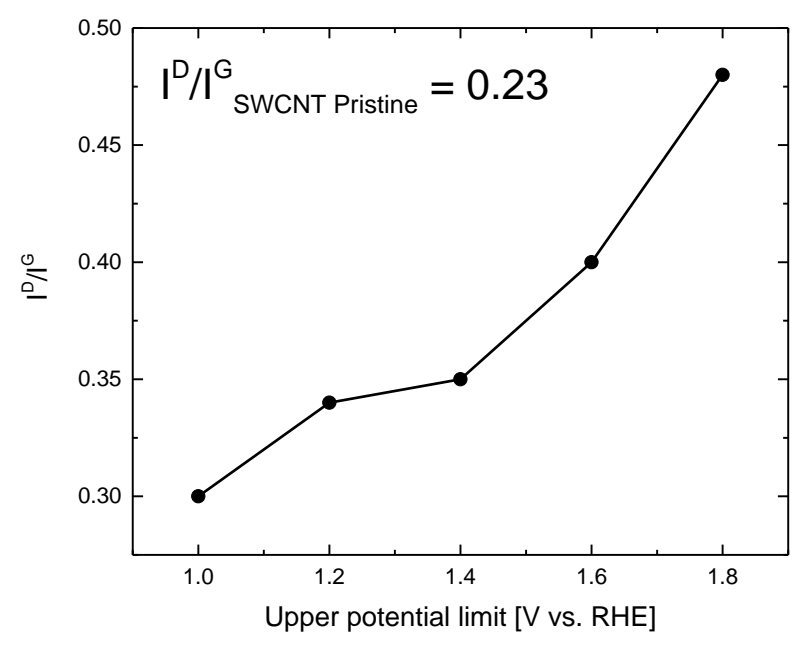

Figure 10. Plot $\mathrm{I}^{\mathrm{D}} / \mathrm{I}^{\mathrm{G}}$ relative intensities as a function of the upper potential limit during the electrochemical modification of SWCNT with 4-APPA.

In the case of SWCNT, it is well-known that Radial Breathing Mode (RBM ) is an environment sensitive property and it is related to the diameter of the tube [54,56-58]. These Raman spectra regions are included in Fig. 9-B. Interestingly, the main features of this region do not significantly change with the functionalization and only some contributions at lower frequencies present a decrease of the intensity with the positive potential limit of functionalization. The diameter of the pristine and modified SWCNT has been determined from the RBM region. The obtained values are between 1.1 to $2.3 \mathrm{~nm}$ in all cases. These values are in agreement with the TEM micrographs 
analyzed previously (Fig. 6). In spite of the application of oxidative conditions and functionalization process in the CNT, the RBM region is still clearly observed and with small changes, suggesting that SWCNTs maintain their tubular structure without suffering strong damages during the electrochemical functionalization. In this sense electrochemical modification produces low structural changes in the CNTs with high increase in the $\mathrm{N}$ and $\mathrm{P}$ species, even at the high positive potential limit used for the modification, what is in agreement with most of the functionalization occurring by wrapping the SWCNT by 4-APPA-based polymer, as deduced from TEM.

\section{Conclusions}

Functionalization of SWCNT with $\mathrm{N}$ and $\mathrm{P}$ functional groups was achieved by electrochemical oxidation of 4-APPA by cyclic voltammetry. The electrochemical oxidation selectively produces oligomer layers that wrap the surface of the SWCNT. Increase in the positive potential of the electrochemical modification demonstrated a high influence in the degree of incorporation of $\mathrm{N}$ and $\mathrm{P}$ species. Thus, when an upper potential limit of $1.4 \mathrm{~V}$ is used, the highest $\mathrm{P}$ incorporation is reached and further potential increase causes loss of P-species probably due to hydrolysis reactions. Several surface redox processes that depend on the applied potential are clearly observed in the voltammograms of the functionalized SWCNT. These redox processes present an important $\mathrm{pH}$ dependence. The well-defined redox processes observed suggests the formation of oligomers with homogenous composition and structure. This conclusion is supported by TEM and Raman spectroscopy. However, the high reversibility and symmetry of the redox processes suggest that covalently bound redox species may also exist.

The high selectivity of the electrochemical process towards monomer oxidation, even at high potentials, and the precise control of the degree of modification of the CNT surface by selecting the electrochemical conditions, make this method an alternative procedure for electrochemical co-functionalization with $\mathrm{P}$ and $\mathrm{N}$ species with the generation of electroactive materials.

\section{Acknowledgements}

The authors would like to thank MINECO, FEDER (MAT2016-76595-R) and ENE2017-90932-REDT for the financial support. A.F.Q.J. gratefully acknowledges Generalitat Valenciana for the financial support through Santiago Grisolia grant (GRISOLIA/2016/084). 


\section{References}

[1] M. Inagaki, F. Kang, M. Toyoda, I. Konno. Advanced Materials Science and Engineering of Carbon, Elsevier, Tsinghua, China, 2014.

[2] T.C. Dinadayalane, J. Leszczynski. Comparative Theoretical Study on the Positional Preference for Functionalization of Two OH and SH Groups with $(5,5)$ Armchair SWCNT, J. Phys. Chem. C. 117 (2013) 14441-14450.

[3] S.T.R. Naqvi, T. Rasheed, D. Hussain, M. Najam ul Haq, S. Majeed, S. shafi, N. Ahmed, R. Nawaz, Modification strategies for improving the solubility/dispersion of carbon nanotubes, J. Mol. Liq. 297 (2020) 111919.

[4] Z. Li, L. Wang, Y. Li, Y. Feng, W. Feng, Carbon-based functional nanomaterials: Preparation, properties and applications, Compos. Sci. Technol. 179 (2019) 1040.

[5] M.S. Ata, R. Poon, A.M. Syed, J. Milne, I. Zhitomirsky, New developments in non-covalent surface modification, dispersion and electrophoretic deposition of carbon nanotubes, Carbon 130 (2018) 584-598.

[6] C. Wang, K. Xia, H. Wang, X. Liang, Z. Yin, Y. Zhang, Advanced Carbon for Flexible and Wearable Electronics, Adv. Mater. 31 (2019) 1801072.

[7] C. Oueiny, S. Berlioz, L. Patout, F.X. Perrin, Aqueous dispersion of multiwall carbon nanotubes with phosphonic acid derivatives, Colloids Surfaces A Physicochem. Eng. Asp. 493 (2016) 41-51.

[8] C. González-Gaitán, R. Ruíz-Rosas, E. Morallón, D. Cazorla-Amorós, Electrochemical Methods to Functionalize Carbon Materials. In: T. Vijay Kumar, T. Manju Kumari, editor. Chemical Functionalization of Carbon MaterialsChemistry and Applications, Taylor and Francis group, CRC Press, Washington, 2016, pp. 230-249.

[9] S.N. Jaisankar, N. Haridharan, A. Murali, P. Sergii, M. Špírková, A.B. Mandal et al. Single-electron transfer living radical copolymerization of SWCNT-g-PMMA via graft from approach, Polymer. 55 (2014) 2959-2966.

[10] Y.-P. Sun, K. Fu, Y. Lin, W. Huang. Functionalized Carbon Nanotubes: Properties and Applications, Acc. Chem. Res. 35 (2002) 1096-1104.

[11] N.S. Komarova, A.G. Krivenko, A.G. Ryabenko, A. V Naumkin. Active forms of oxygen as agents for electrochemical functionalization of SWCNTs, Carbon. 53 (2013) 188-196.

[12] N.M. Mubarak, J.N. Sahu, J.R. Wong, N.S. Jayakumar, P. Ganesan, and E.C. Abdullah. Overview on the Functionalization of Carbon Nanotubes. In: T. Vijay Kumar, T. Manju Kumari, editor. Chemical Functionalization of Carbon Materials-Chemistry and Applications, Taylor and Francis group, CRC Press, Washington, 2016, pp. 230-249. 
[13] J.U. Lee, J. Huh, K.H. Kim, C. Park, W.H. Jo. Aqueous suspension of carbon nanotubes via non-covalent functionalization with oligothiophene-terminated poly(ethylene glycol), Carbon. 45 (2007) 1051-1057.

[14] M. Boháčová, K. Zetková, P. Knotek, D. Bouša, K. Friess, P. Č́́hal, et al. Mildly oxidized SWCNT as new potential support membrane material for effective $\mathrm{H}_{2} / \mathrm{CO}_{2}$ separation, Appl. Mater. Today. 15 (2019) 335-342.

[15] D. Kumar, P. Jha, A. Chouksey, J.S.B.S. Rawat, R.P. Tandon, P.K. Chaudhury. 4(Hexafluoro-2-hydroxy isopropyl)aniline functionalized highly sensitive flexible SWCNT sensor for detection of nerve agent simulant dimethyl methylphosphonate, Mater. Chem. Phys. 181 (2016) 487-494.

[16] A.S. Adekunle, J. Pillay, K.I. Ozoemena. Probing the electrochemical behaviour of SWCNT-cobalt nanoparticles and their electrocatalytic activities towards the detection of nitrite at acidic and physiological pH conditions, Electrochim. Acta. 55 (2010) 4319-4327.

[17] R.J. Chen, Y. Zhang, D. Wang, H. Dai. Noncovalent Sidewall Functionalization of Single-Walled Carbon Nanotubes for Protein Immobilization, J. Am. Chem. Soc. 123 (2001) 3838-3839.

[18] M.-B. Ebrahim-Habibi, M. Ghobeh, F.A. Mahyari, H. Rafii-Tabar, P. Sasanpour. An investigation into non-covalent functionalization of a single-walled carbon nanotube and a graphene sheet with protein G:A combined experimental and molecular dynamics study, Sci. Rep. 9 (2019) 1273.

[19] R.A. Fraser, K. Stoeffler, B. Ashrafi, Y. Zhang, B. Simard. Large-Scale Production of PMMA/SWCNT Composites Based on SWCNT Modified with PMMA, ACS Appl. Mater. Interfaces. 4 (2012) 1990-1997.

[20] S.A. Ntim, O. Sae-Khow, F.A. Witzmann, S. Mitra. Effects of polymer wrapping and covalent functionalization on the stability of MWCNT in aqueous dispersions, J. Colloid Interface Sci. 355 (2011) 383-388.

[21] S.S.J. Aravind, P. Baskar, T.T. Baby, R.K. Sabareesh, S. Das, S. Ramaprabhu. Investigation of Structural Stability, Dispersion, Viscosity, and Conductive Heat Transfer Properties of Functionalized Carbon Nanotube Based Nanofluids, J. Phys. Chem. C. 115 (2011) 16737-16744.

[22] T. Ramanathan, F.T. Fisher, R.S. Ruoff, L.C. Brinson. Amino-Functionalized Carbon Nanotubes for Binding to Polymers and Biological Systems, Chem. Mater. 17 (2005) 1290-1295.

[23] M.T. Martínez, M.A. Callejas, A.M. Benito, M. Cochet, T. Seeger, A. Ansón, et al. Sensitivity of single wall carbon nanotubes to oxidative processing: structural modification, intercalation and functionalisation, Carbon 41 (2003) 2247-2256.

[24] P.-C. Ma, N.A. Siddiqui, G. Marom, J.-K. Kim. Dispersion and functionalization 
of carbon nanotubes for polymer-based nanocomposites: A review, Compos. Part A Appl. Sci. Manuf. 41 (2010) 1345-1367.

[25] M. Holzinger, J. Abraham, P. Whelan, R. Graupner, L. Ley, F. Hennrich, et al. Functionalization of Single-Walled Carbon Nanotubes with (R-)Oxycarbonyl Nitrenes, J. Am. Chem. Soc. 125 (2003) 8566-8580.

[26] M. Theodore, M. Hosur, J. Thomas, S. Jeelani. Influence of functionalization on properties of MWCNT-epoxy nanocomposites, Mater. Sci. Eng. A. 528 (2011) 1192-1200.

[27] D. Bélanger, J. Pinson. Electrografting: a powerful method for surface modification, Chem. Soc. Rev. 40 (2011) 3995-4048.

[28] M.A. Ghanem, I. Kocak, A. Al-Mayouf, M. AlHoshan, P.N. Bartlett. Covalent modification of carbon nanotubes with anthraquinone by electrochemical grafting and solid phase synthesis, Electrochim. Acta. 68 (2012) 74-80.

[29] P. Allongue, M. Delamar, B. Desbat, O. Fagebaume, R. Hitmi, J. Pinson, et al. Covalent Modification of Carbon Surfaces by Aryl Radicals Generated from the Electrochemical Reduction of Diazonium Salts, J. Am. Chem. Soc. 119 (1997) 201-207.

[30] C. González-Gaitán, R. Ruiz-Rosas, E. Morallón, D. Cazorla-Amorós. Functionalization of carbon nanotubes using aminobenzene acids and electrochemical methods. Electroactivity for the oxygen reduction reaction, Int. J. Hydrogen Energy. 40 (2015) 11242-11253.

[31] C. González-Gaitán, R. Ruiz-Rosas, H. Nishihara, T. Kyotani, E. Morallón, D. Cazorla-Amorós. Successful functionalization of superporous zeolite templated carbon using aminobenzene acids and electrochemical methods, Carbon. 99 (2016) $157-166$.

[32] A. Gabe, R. Ruiz-Rosas, E. Morallón, D. Cazorla-Amorós. Understanding of oxygen reduction reaction by examining carbon-oxygen gasification reaction and carbon active sites on metal and heteroatoms free carbon materials of different porosities and structures, Carbon. 148 (2019) 430-440.

[33] I. Such-Basáñez, M.C. Román-Martínez, C. Salinas-Martínez de Lecea. Ligand adsorption on different activated carbon materials for catalyst anchorage, Carbon. 42 (2004) 1357-1361.

[34] D. Salinas-Torres, F. Huerta, F. Montilla, E. Morallón. Study on electroactive and electrocatalytic surfaces of single walled carbon nanotube-modified electrodes, Electrochim. Acta. 56 (2011) 2464-2470.

[35] A. Bard, L. Faulkner. Electrochemical Methods: Fundamental and Applications, 2nd ed., John Wiley \& Sons, Ltd, Austin, 2000.

[36] M. Probst, R. Holze. A systematic spectroelectrochemical investigation of alkyl- 
substituted anilines and their polymers, Macromol. Chem. Phys. 198 (1997) 14991509.

[37] M.R. Nateghi, M. Zahedi, M.H. Mosslemin, S. Hashemian, S. Behzad, A. Minnai. Autoacceleration/degradation of electrochemical polymerization of substituted anilines, Polymer. 46 (2005) 11476-11483.

[38] A. Benyoucef, F. Huerta, M.I. Ferrahi, E. Morallon. Voltammetric and in situ FTIRS study of the electropolymerization of o-aminobenzoic acid at gold and graphite carbon electrodes: Influence of $\mathrm{pH}$ on the electrochemical behaviour of polymer films, J. Electroanal. Chem. 624 (2008) 245-250.

[39] B. Wang, J. Tang, F. Wang. Electrochemical polymerization of aniline, Synth. Met. 18 (1987) 323-328.

[40] J. Quílez-Bermejo, A. Ghisolfi, D. Grau-Marín, E. San-Fabián, E. Morallón, D. Cazorla-Amorós. Post-synthetic efficient functionalization of polyaniline with phosphorus-containing groups. Effect of phosphorus on electrochemical properties, Eur. Polym. J. 119 (2019) 272-280.

[41] L.R. Radovic, I.F. Silva, J.I. Ume, J.A. Menéndez, C.A.L.Y. Leon, A.W. Scaroni. An experimental and theoretical study of the adsorption of aromatics possessing electron-withdrawing and electron-donating functional groups by chemically modified activated carbons, Carbon. 35 (1997) 1339-1348.

[42] L.R. Radovic, C. Moreno-Castilla, J. Rivera-Utrilla, Carbon Materials as adsorbents in aqueous solution. In: Radovic, L. R. editor. Chemistry and physics of carbon, Vol 27, Marcel Dekker, CRC Press, New York, 2000. pp. 227-405.

[43] B. Martínez-Sánchez, Síntesis y caracterización electroquímica de polianilinas modificadas con grupos fosfónicos, Universidad de Alicante, Master thesis, 2019.

[44] H. Tang, A. Kitani, T. Yamashita, S. Ito. Highly sulfonated polyaniline electrochemically synthesized by polymerizing aniline-2,5-disulfonic acid and copolymerizing it with aniline, Synth. Met. 96 (1998) 43-48.

[45] G. Jürmann, D.J. Schiffrin, K. Tammeveski. The pH-dependence of oxygen reduction on quinone-modified glassy carbon electrodes, Electrochim. Acta. 53 (2007) 390-399.

[46] Z. Wang, Y. Dong, H. Li, Z. Zhao, H. Bin Wu, C. Hao, et. al. Enhancing lithiumsulphur battery performance by strongly binding the discharge products on aminofunctionalized reduced graphene oxide, Nat. Commun. 5 (2014) 5002.

[47] M. Abidi, S. López-Bernabeu, F. Huerta, F. Montilla, S. Besbes-Hentati, E. Morallón. Spectroelectrochemical study on the copolymerization of oaminophenol and aminoterephthalic acid, Eur. Polym. J. 91 (2017) 386-395.

[48] T. Cordero-Lanzac, J.M. Rosas, F.J. García-Mateos, J.J. Ternero-Hidalgo, J. Palomo, J. Rodríguez-Mirasol, et. al. Role of different nitrogen functionalities on 
the electrochemical performance of activated carbons, Carbon. 126 (2018) 65-76.

[49] S. Baskar, C.-W. Liao, J.-L. Chang, J.-M. Zen. Electrochemical synthesis of electroactive poly(melamine) with mechanistic explanation and its applicability to functionalize carbon surface to prepare nanotube-nanoparticles hybrid, Electrochim. Acta. 88 (2013) 1-5.

[50] A. Adenier, M.M. Chehimi, I. Gallardo, J. Pinson, N. Vilà. Electrochemical Oxidation of Aliphatic Amines and Their Attachment to Carbon and Metal Surfaces, Langmuir. 20 (2004) 8243-8253.

[51] R. Berenguer, R. Ruiz-Rosas, A. Gallardo, D. Cazorla-Amorós, E. Morallón, H. Nishihara, et al. Enhanced electro-oxidation resistance of carbon electrodes induced by phosphorus surface groups, Carbon. 95 (2015) 681-689.

[52] F. Quesada-Plata, R. Ruiz-Rosas, E. Morallón, D. Cazorla-Amorós, Activated Carbons Prepared through $\mathrm{H}_{3} \mathrm{PO}_{4}$-Assisted Hydrothermal Carbonisation from Biomass Wastes: Porous Texture and Electrochemical Performance, Chempluschem. 81 (2016) 1349-1359.

[53] Y. Chen, L.-R. Guo, W. Chen, X.-J. Yang, B. Jin, L.-M. Zheng, et al. 3mercaptopropylphosphonic acid modified gold electrode for electrochemical detection of dopamine, Bioelectrochemistry. 75 (2009) 26-31.

[54] D.-S. Yang, D. Bhattacharjya, S. Inamdar, J. Park, J.-S. Yu. Phosphorus-Doped Ordered Mesoporous Carbons with Different Lengths as Efficient Metal-Free Electrocatalysts for Oxygen Reduction Reaction in Alkaline Media, J. Am. Chem. Soc. 134 (2012) 16127-16130.

[55] S.A. Paniagua, P.J. Hotchkiss, S.C. Jones, S.R. Marder, A. Mudalige, F.S. Marrikar, et al. Phosphonic Acid Modification of Indium-Tin Oxide Electrodes: Combined XPS/UPS/Contact Angle Studies, J. Phys. Chem. C. 112 (2008) 78097817.

[56] S.E. Koh, K.D. McDonald, D.H. Holt, C.S. Dulcey, J.A. Chaney, P.E. Pehrsson. Phenylphosphonic Acid Functionalization of Indium Tin Oxide: Surface Chemistry and Work Functions, Langmuir. 22 (2006) 6249-6255.

[57] T. Amaya, I. Kurata, Y. Inada, T. Hatai, T. Hirao, Synthesis of phosphonic acid ring-substituted polyanilines via direct phosphonation to polymer main chains, RSC Adv. 7 (2017) 39306-39313.

[58] S. Leyva-García, E. Morallón, D. Cazorla-Amorós, F. Béguin, D. Lozano-Castelló. New insights on electrochemical hydrogen storage in nanoporous carbons by in situ Raman spectroscopy, Carbon. 69 (2014) 401-408.

[59] S. Leyva-García, K. Nueangnoraj, D. Lozano-Castelló, H. Nishihara, T. Kyotani, E. Morallón, et al. Characterization of a zeolite-templated carbon by electrochemical quartz crystal microbalance and in situ Raman spectroscopy, 
Carbon. 89 (2015) 63-73.

[60] M.S. Dresselhaus, A. Jorio, R. Saito. Characterizing Graphene, Graphite, and Carbon Nanotubes by Raman Spectroscopy, Annu. Rev. Condens. Matter Phys. 1 (2010) 89-108.

[61] R. Voggu, C.S. Rout, A.D. Franklin, T.S. Fisher, C.N.R. Rao. Extraordinary Sensitivity of the Electronic Structure and Properties of Single-Walled Carbon Nanotubes to Molecular Charge-Transfer, J. Phys. Chem. C. 112 (2008) 1305313056.

[62] R. Gupta, B.P. Singh, V.N. Singh, T.K. Gupta, R.B. Mathur. Origin of radial breathing mode in multiwall carbon nanotubes synthesized by catalytic chemical vapor deposition, Carbon. 66 (2014) 724-726.

[63] G. Ruiz-Soria, T. Susi, M. Sauer, K. Yanagi, T. Pichler, P. Ayala. On the bonding environment of phosphorus in purified doped single-walled carbon nanotubes, Carbon. 81 (2015) 91-95.

[64] P.-C. Wang, Y.-C. Liao, Y.-L. Lai, Y.-C. Lin, C.-Y. Su, C.-H. Tsai, et al. Conversion of pristine and p-doped sulfuric-acid-treated single-walled carbon nanotubes to n-type materials by a facile hydrazine vapor exposure process, Mater. Chem. Phys. 134 (2012) 325-332. 